\title{
Production of fructo-oligosaccharides by Aspergillus ibericus and their chemical characterization
}

\author{
C. Nobre $^{\mathrm{a}, *}$, E.G. Alves Filho ${ }^{\mathrm{b}, \mathrm{c}}$, F.A.N. Fernandes ${ }^{\mathrm{b}, \mathrm{d}}$, E.S. Brito ${ }^{\mathrm{c}}$, S. Rodrigues ${ }^{\mathrm{b}}$, J.A. Teixeira ${ }^{\mathrm{a}}$, \\ L.R. Rodrigues ${ }^{a}$ \\ a Centre of Biological Engineering, University of Minho, Campus de Gualtar, 4710-057 Braga, Portugal \\ b LABIOTEC, Food Technology Department, Federal University of Ceará, Fortaleza, CE, Brazil \\ c Embrapa Agroindustria Tropical, Fortaleza, CE, Brazil \\ d Chemical Engineering Department, Federal University of Ceará, Campus do Pici, Bloco 709, CEP 60440-900 Fortaleza, CE, Brazil
}

\section{A R T I C L E I N F O}

\section{Keywords:}

Fructo-oligosaccharides

Aspergillus ibericus

Chemical structure

Experimental design

Production yield optimization

\begin{abstract}
A B S T R A C T
A great demand for prebiotics is driving the search for new sources of fructo-oligosaccharides (FOS) producers and for FOS with differentiated functionalities. In the present work, FOS production by a new isolated strain of Aspergillus ibericus was evaluated. The temperature of fermentation and initial $\mathrm{pH}$ were optimized in shaken flask to yield a maximal FOS production, through a central composite experimental design. FOS were produced in a one-step bioprocess using the whole cells of the microorganism. The model $\left(\mathrm{R}^{2}=0.918\right)$ predicted a yield of 0.56 , experimentally $0.53 \pm 0.03 \mathrm{~g}_{\mathrm{FOS}} \cdot \mathrm{g}_{\text {initial sucrose }}{ }^{-1}$ was obtained $\left(37.0{ }^{\circ} \mathrm{C}\right.$ and a pH of 6.2$)$. A yield of $0.64 \pm 0.02 \mathrm{~g}_{\mathrm{FOS}} \cdot \mathrm{g}_{\text {initial sucrose }}{ }^{-1}$ was obtained in the bioreactor, at $38 \mathrm{~h}$, with a content of $118 \pm 4 \mathrm{~g} . \mathrm{L}^{-1} \mathrm{in}$ FOS and a purity of $56 \pm 3 \%$. The chemical structure of the FOS produced by $A$. ibericus was determined by HPLC and NMR. FOS were identified as 1-kestose, nystose, and $1^{\mathrm{F}}$-fructofuranosylnystose. In conclusion, $A$. ibericus was found to be a good alternative FOS producer.
\end{abstract}

\section{Introduction}

Several aspects of human health are influenced by the microbial communities colonizing the different regions of the human gut. Via fermentation of non-digestible carbohydrates, e.g. oligosaccharides, the gut microbiota contributes with energy and nutrient supply to the host (Flint, Scott, Louis, \& Duncan, 2012). The daily intake of specific oligosaccharides, namely fructo-oligosaccharides (FOS), has proved to be effective in the manipulation of the composition and functionality of the colonic microbiota (Scheid, Moreno, Maróstica Junior, \& Pastore, 2013; Rastall et al., 2005). FOS consumption by the probiotic bacteria results in (a) an increase of the expression or change in the composition of short-chain fatty acids; (b) an increased fecal weight; (c) a mild decrease in luminal colon $\mathrm{pH}$; (d) a decrease in nitrogenous end-products; (e) an increased expression of the binding proteins or active carriers associated with mineral absorption, and immune system regulation (Younis, Ahmad, \& Jahan, 2015). These changes are reflected in a great number of health benefits for the humans such as reducing or preventing gastroenteritis, inflammatory bowel disease, colon cancer, allergies, obesity, cardiovascular disease, osteoporosis, among others
(Sabater-Molina, Larqué, Torrella, \& Zamora, 2009; Slavin, 2013; Wang, 2009). Therefore, FOS are one of the most commonly commercialized prebiotics (Nobre, Cerqueira, Rodrigues, Vicente, \& Teixeira, 2015).

FOS are produced from the transfructosylation of sucrose by enzymes contained in a number of microorganisms. Fungi are the most studied microorganisms for FOS production, particularly Aureobasidium pullulans (a yeast-like fungus), Aspergillus sp. and Penicillium sp. Detailed information on microorganisms with transfructosylating activity that are able to produce FOS can be found in recent reviews (Bali, Panesar, Bera, \& Panesar, 2015; Dominguez, Rodrigues, Lima, \& Teixeira, 2013; Ganaie, Lateef, \& Gupta, 2014).

The main drawback in the production of FOS using microbial enzymes is the low yields achieved between 0.55 and $0.60 \mathrm{~g}_{\text {Fos }} \cdot g_{\text {initial }}$ sucrose $^{-1} \quad$ (Nishizawa, Nakajima, \& Nabetani, 2001; Sangeetha, Ramesh, \& Prapulla, 2005). Fructosyltransferase (FTase) enzymes are inhibited by glucose, which is the main product released in the fermentative broth during the FOS synthesis. Moreover, the FOS formed are simultaneously hydrolyzed back to the single monomer forms by the action of the same enzymes. Therefore, many attempts have been done

\footnotetext{
* Corresponding author. Centre of Biological Engineering, University of Minho, Campus de Gualtar, 4710-057 Braga, Portugal.

E-mail addresses: clarissenobre@gmail.com, clarissenobre@deb.uminho.pt (C. Nobre), elenilson.godoy@yahoo.com.br (E.G. Alves Filho), fabiano@ufc.br (F.A.N. Fernandes), edy.brito@embrapa.br (E.S. Brito), sueli@ufc.br (S. Rodrigues), jateixeira@deb.uminho.pt (J.A. Teixeira), lrmr@deb.uminho.pt (L.R. Rodrigues).
} 
to increase the production yields of FOS in fermentative broths such as the use of immobilized enzymes and treatment with pressurized fluids (Castro, Nobre, Duprez, De Weireld, \& Hantson, 2017; Silva et al., 2013), microbial treatments or mixed enzymes (Nobre et al., 2016; Nobre, Teixeira, \& Rodrigues, 2015). One-step fermentation, where the whole cells of $A$. pullulans instead of the isolated enzymes are used, has also shown to increase yields up to $0.63 \mathrm{~g}_{\text {Fos. }}$ g $_{\text {initial }}$ sucrose $^{-1}$ (Dominguez et al., 2012; Nobre et al., 2016).

The great current demand for prebiotics, in particular FOS, requires a continuous search for new microorganisms capable of producing FTase with a good transfructosylation activity that can be further used to produce FOS. Aspergillus ibericus MUM 03.49 was isolated from Portuguese wine grapes (Serra et al., 2006). The strain exhibits potential for FOS formation since a pronounced positive colour reaction was obtained while screening the transfructosylation activity of the microorganism in plate tests (Dominguez, Santos, Teixeira, \& Lima, 2006). Therefore, the aim of this work was to evaluate the production of FOS by the new isolated $A$. ibericus MUM 03.49 strain, by means of a onestep fermentation. Fermentation conditions, namely temperature and $\mathrm{pH}$ were optimized in shaken flasks using a central composite design and the process was further scaled-up to a $2 \mathrm{~L}$ bioreactor. Since this is the first report on FOS obtained by this strain, the sugar mixture obtained was also analyzed by HPLC and chemically characterized by NMR to identify the chemical structures and compare it with other commercially available mixtures, namely regarding the linkage between the sugar monomers that may have an important impact on the prebiotic functionality of the oligosaccharide (Li et al., 2015).

\section{Materials and methods}

\subsection{Microorganisms and culture conditions}

The fungus Aspergillus ibericus MUM 03.49 from Micoteca da Universidade do Minho (MUM) culture collection (Braga, Portugal) was used. The strain was revived on Czapeck Dox (Oxoid, UK) at $25^{\circ} \mathrm{C}$ from a frozen glycerol stock and maintained on agar Petri plates with the same medium at $4{ }^{\circ} \mathrm{C}$. Every month, the strain was sub-cultured. A concentrated spore suspension was prepared from a 7-day-old culture plate by scrapping the spores with a $0.1 \%(\mathrm{w} / \mathrm{v})$ solution of Tween 80 (Panreac, AppliChem, Spain). Afterwards, the spore concentration of the suspension was adjusted to $9 \times 10^{6}$ spores. $\mathrm{mL}^{-1}$ using an improved Neubauer chamber.

\subsection{Experimental design and data analysis}

Temperature and $\mathrm{pH}$ conditions were optimized by experimental design. Parameters were selected according to preliminary studies where a broader range of temperature $\left(20.9-49.1{ }^{\circ} \mathrm{C}\right)$ was investigated under pH 6.0 (Gomes, 2009). The influence of agitation was not evaluated at this stage since the main goal of the work was to scale-up the process to a bioreactor size, in which the agitation mode is significantly different from the one obtained in an orbital shaker. The influence of temperature and $\mathrm{pH}$ (both independent variables) on the FOS production yield (dependent variable) was assessed through a $2^{2}$ full-factorial central composite design (CCD), with 3 central points. For the statistical analysis, the independent variables were coded according to Eq. (1), where each independent variable is represented by xi (coded value), $\mathrm{Xi}$ (real value), $\mathrm{XO}$ (real value at the central point), and $\Delta \mathrm{Xi}$ (step change value):

$\mathrm{x}_{\mathrm{i}}=\left(\mathrm{X}_{\mathrm{i}}-\mathrm{X}_{0}\right) / \Delta \mathrm{X}_{\mathrm{i}}$

The range and the levels of the independent variables studied are given in Table 1.

Experimental results were fitted with a second-order polynomial equation by multiple regression analysis. The quadratic mode for
Table 1

Experimental range and levels of the independent process variables according to the $2^{2}$ full-factorial central composite design.

\begin{tabular}{lllll}
\hline Independent variables & Symbol & \multicolumn{2}{l}{ Range and levels } \\
\cline { 3 - 5 } & & -1 & 0 & 1 \\
\hline Temperature $\left({ }^{\circ} \mathrm{C}\right)$ & $\mathrm{X}_{1}$ & 25 & 30 & 35 \\
$\mathrm{pH}$ & $\mathrm{X}_{2}$ & 5.5 & 6 & 6.5 \\
\hline
\end{tabular}

predicting the optimal point was expressed according to Eq. (2), where $\mathrm{Y}$ represents the response variable (FOS production yield), $\beta 0$ is the interception coefficient, $\beta_{\mathrm{i}}$ are the regression coefficients, and $\mathrm{X}_{1}$ and $\mathrm{X}_{2}$ represent the independent variables (temperature and $\mathrm{pH}$, respectively):

$Y=\beta 0+\beta_{1} X_{1}+\beta_{2} X_{2}+\beta_{1} X_{1}^{2}+\beta_{1} \beta_{2} X_{1} X_{2}+\beta_{2} X_{2}{ }^{2}$

The Statistica 10.0 software (Statsoft, USA) was used for the experimental design and regression analysis of the experimental data. The effects of linear, quadratic and interactive terms of the independent variables on the chosen dependent variables were evaluated by the model. The quality of the fitted polynomial model was statistically checked by the magnitude of the coefficient of determination $\mathrm{R}^{2}$ and its statistical significance was checked by the $F$-test analysis of variance (ANOVA). The coefficients of the response surface were evaluated using the student $t$-test.

Data were compared using one-way ANOVA followed by a Tukey's multiple comparison test with 95\% confidence level. Positive effects were considered significant for $p$-values lower than 0.05 .

\subsection{FOS production in shaken flasks}

The experimental design runs were performed in $250 \mathrm{~mL}$ glass flasks containing $50 \mathrm{~mL}$ of the following fermentation medium: $200 \mathrm{~g} . \mathrm{L}^{-1}$ sucrose, 5.0 g.L $\mathrm{L}^{-1} \mathrm{NaNO}_{3}, 4.0$ g.L ${ }^{-1} \mathrm{KH}_{2} \mathrm{PO}_{4}, 0.5$ g.L ${ }^{-1} \mathrm{KCl}, 0.35$ g.L ${ }^{-1}$ $\mathrm{K}_{2} \mathrm{SO}_{4}, 0.5$ g.L ${ }^{-1} \mathrm{MgSO}_{4} .7 \mathrm{H}_{2} \mathrm{O}$ and 0.01 g.L ${ }^{-1} \mathrm{FeSO}_{4} .7 \mathrm{H}_{2} \mathrm{O}$ (Nobre et al., 2016). Sucrose and $\mathrm{FeSO}_{4} \cdot 7 \mathrm{H}_{2} \mathrm{O}$ solutions were sterilized by filtration $(0.2 \mu \mathrm{m})$ and the other salt solutions were autoclaved at $121{ }^{\circ} \mathrm{C}$ for $15 \mathrm{~min}$. The fermentation medium was inoculated with $1 \mathrm{~mL}$ of the spore suspension solution $\left(9 \times 10^{6}\right.$ spores. $\left.\mathrm{mL}^{-1}\right)$ and agitated at $150 \mathrm{rpm}$, in an orbital shaker (Certomat ${ }^{\circ}$, B.Braun Biotech International GmbH, Germany), for $44 \mathrm{~h}$.

Several samples were taken at different time points for further determination of sugar concentration. Different combinations of temperature and initial $\mathrm{pH}$ were tested according to the experimental design (Table 1). All chemicals used were of analytical grade.

\subsection{FOS production in bioreactor}

The inoculum was prepared in a $250 \mathrm{~mL}$ flask, containing $100 \mathrm{~mL}$ of fermentation medium (same composition as described in section 2.3 except for sucrose (100 g.L $\left.\mathrm{L}^{-1}\right)$ ). The fermentation medium was seeded with $1 \mathrm{~mL}$ of the spore suspension solution $\left(9 \times 10^{6}\right.$ spores.mL $\left.{ }^{-1}\right)$ and grown for 3 days at $35{ }^{\circ} \mathrm{C}$ and $150 \mathrm{rpm}$. Fermentations were carried out in a $2 \mathrm{~L}$ bioreactor (Autoclavable Benchtop Fermenter Type R'ALF, Bioengineering AG, Wald, Switzerland) with a working volume of $1 \mathrm{~L}$ of medium with the same composition as described in section 2.3. Assays were conducted for $62 \mathrm{~h}$ (time point at which it can be assured that the maximal production of FOS has been reached), at $200 \mathrm{rpm}$ under the optimized temperature and $\mathrm{pH}$ conditions obtained by the experimental design. Samples were collected during the fermentation for sugar concentration determination. Fermentations were carried out in triplicate. 


\subsection{Sugar analysis}

The sugars concentration of the samples was determined by highperformance liquid chromatography (HPLC). A modular liquid chromatograph (Shimadzu) equipped with a Prevail Carbohydrate ES column ( $5 \mu \mathrm{m}, 25 \times 0.46 \mathrm{~cm}$ length $\mathrm{x}$ diameter) from Alltech, was used at $25{ }^{\circ} \mathrm{C}$. Samples were eluted with a mixture of acetonitrile (HPLC Grade, Carlo Erba, France) and 0.04\% ammonium hydroxide (HPLC Grade, Sigma-Aldrich, Germany) in water (70:30, v/v), at a flow rate of $1.0 \mathrm{~mL} \cdot \mathrm{min}^{-1}$ (Nobre et al., 2009). Samples were detected with a Sedex 55 evaporative light scattering detector (ELSD) (Sedere, Alfortville, France) working with a drift tube temperature set at $50{ }^{\circ} \mathrm{C}$ and nitrogen gas as nebulizing gas, at a pressure of 3.5 bar. The chromatographic signal was recorded and further integrated using the software LabSolutions (Shimadzu).

FOS standards were acquired from Wako Pure Chemical Industries, Ltd. (Osaka, Japan). Sucrose and fructose standards were obtained from Merck Co. (Darmstadt, Germany) and glucose from VWR International (Belgium).

\subsection{FOS mixtures}

The chemical structure of FOS obtained from three different sources was analyzed by Nuclear Magnetic Resonance (NMR). The mixtures herein studied were: (IB) the FOS mixture produced in this work by $A$. ibericus; (AP) a FOS mixture produced by A. pullulans CCY 27-1-94 in our previous work (Nobre et al., 2016), identified as 1-kestose, 1-nystose and $1^{\mathrm{F}}$-fructofuranosylnystose (Vandáková, Platková, Antošová, Báleš, \& Polakovič, 2004); and the commercially available Actilight mixture (Beghin Meiji, France) that is produced from sucrose through fructosyl-transferase of the Aspergillus niger. The chemical structure of each FOS was compared with the standard FOS from Wako, identified as 1-kestose $\left(\mathrm{GF}_{2}\right)$, 1-nystose $\left(\mathrm{GF}_{3}\right)$ and $1^{\mathrm{F}}$-fructofuranosylnystose $\left(\mathrm{GF}_{4}\right)$ (Neuss, Germany).

The FOS mixtures AP and IB were purified in an activated charcoal column, as described by Nobre, Teixeira, \& Rodrigues, 2012. Fractions desorbed with $20 \%$ of ethanol were further used for the characterization tests. The AP mixture exhibited the following composition in FOS (\% w/w): $33 \%$ of $\mathrm{GF}_{2}, 53 \%$ of $\mathrm{GF}_{3}$ and $7 \%$ of $\mathrm{GF}_{4}$. The IB mixture was composed by $39 \%$ of $\mathrm{GF}_{2}, 50 \%$ of $\mathrm{GF}_{3}$ and $4 \%$ of $\mathrm{GF}_{4}$.

Actilight is a food ingredient commercialized by Beghin Meiji (France), which is produced from sucrose through fructosyl-transferase from Aspergillus niger. The commercial mixture Actilight 950S (Beghin Meiji, France) comprises (\% in dry matter): $4.7 \%$ fructose + glucose + sucrose, $37.1 \% \mathrm{GF}_{2}, 47.7 \% \mathrm{GF}_{3}$, and $15.2 \% \mathrm{GF}_{4}$ (information obtained from the supplier).

\subsection{NMR analysis}

The NMR experiments were performed in an Agilent $600-\mathrm{MHz}$ spectrometer equipped with a $5 \mathrm{~mm}\left(\mathrm{H}-\mathrm{F} /{ }^{15} \mathrm{~N}-{ }^{31} \mathrm{P}\right)$ inverse detection One Probe ${ }^{\mathrm{TM}}$ with actively shielded Z-gradient. The ${ }^{1} \mathrm{H}$ NMR spectra were performed using the PRESAT pulse sequence for non-deuterated water suppression ( $\delta$ 4.77). The data were acquired with the RF pulse (p1) calibrated and 8 scans, 65.536 of time domain points for a spectral window of $10 \mathrm{ppm}$, acquisition time of $5.0 \mathrm{~s}$ and a relaxation delay of $10.0 \mathrm{~s}$. The spectra were calibrated externally to the TMSP- $\mathrm{d}_{4}$ resonance ( $\delta 0.0$ ) and temperature controlled to $298 \mathrm{~K}$. The ${ }^{13} \mathrm{C}$ NMR spectra were acquired 10k scans, 32.768 of time domain points for a spectra window of $250 \mathrm{ppm}$, acquisition time of $0.87 \mathrm{~s}$ and a relaxation delay of $1.0 \mathrm{~s}$.

Two-dimensional (2D) NMR experiments were acquired using the standard spectrometer library pulse sequences. ${ }^{1} \mathrm{H}_{-}{ }^{1} \mathrm{H}$ COSY experiments were obtained with spectral width of $18,028.1 \mathrm{~Hz}$ in both dimensions; $1442 \times 200$ data matrix; 16 scans per 11 increment and relaxation delay of $1.0 \mathrm{~s}$. One-bond ${ }^{1} \mathrm{H}_{-}{ }^{13} \mathrm{C}$ HSQC experiments were acquired with an evolution delay of $1.7 \mathrm{~ms}$ for an average $1 J(\mathrm{C}, \mathrm{H})$ of
$145 \mathrm{~Hz} ; 1442 \times 200$ data matrix; 32 scans per t1 increment; spectral widths of $9615.4 \mathrm{~Hz}$ in $\mathrm{f} 2$ and $30,165.9 \mathrm{~Hz}$ in $\mathrm{f} 1$ and relaxation delay of 1.0 s. Long-range ${ }^{1} \mathrm{H}_{-}{ }^{13} \mathrm{C}$ HMBC experiments were recorded with an evolution delay of $50.0 \mathrm{~ms}$ for ${ }^{\mathrm{LR}} \mathrm{J}(\mathrm{C}, \mathrm{H})$ of $10 \mathrm{~Hz} ; 1442 \times 200$ data matrix; 64 scans per t1 increment; spectral widths of $9615.4 \mathrm{~Hz}$ in $\mathrm{f} 2$ and $30,165.9 \mathrm{~Hz}$ in $\mathrm{f} 1$ and relaxation delay of $1.0 \mathrm{~s}$.

\section{Result and discussion}

\subsection{Effect of the operating conditions on FOS production}

A maximum temperature of $35{ }^{\circ} \mathrm{C}$ was established since higher values influence negatively the growth of the microorganism as found in a previous work (Gomes, 2009). The $\mathrm{pH}$ variation was around 6.0 as good FOS production by whole cells microorganisms were reported at this $\mathrm{pH}$ (Dominguez et al., 2012; Gomes, 2009; Nobre et al., 2016).

After identifying the variables affecting the FOS production yield, the experimental values were fitted to a second-order equation, obtained by multiple regression analysis.

The $F$ test and ANOVA analysis were used as significance criteria for the fitted model. The model was considered statistically significant at 95\% confidence level since the calculated $F$ value (11.22) was higher than the listed one $\left(\mathrm{F}_{5,5}=5.05\right)$. The quality of the quadratic fit was analyzed based on the coefficient of determination $\mathrm{R}^{2}$. The model explained $91.8 \%$ of the dependent variable's variability $\left(R^{2}=0.918\right)$ with a good adjusted determination coefficient $\left(R_{\text {adjsuted }}^{2}=0.836\right)$. Given the $\mathrm{R}^{2}$ value, the prediction performance of the proposed model in the experimental region was found to be accurate.

The effect of temperature and $\mathrm{pH}$ on the production yield is provided in Table 3. Results showed that both temperature and $\mathrm{pH}$ present a statistically significant effect on the FOS production yield. The temperature is the parameter that most influences the yield, with an estimated effect of 7.046. The positive effect of the temperature means that an increase of the temperature level will lead to higher FOS production yields. On the other hand, the effects of the interaction between the studied variables were not significant at a 95\% confidence level. Therefore, a simplified model is proposed by the elimination of the statistically insignificant terms. The coefficients determined for the model are given in Eq. (3), where $\mathrm{X}_{1}$ and $\mathrm{X}_{2}$ represent the coded levels for the initial temperature and $\mathrm{pH}$, respectively:

FOS yield production $=-582.53+2.67 \mathrm{X}_{1}+190.33 \mathrm{X}_{2}-16.06 \mathrm{X}_{2}{ }^{2}(3)$

The values predicted by the model are presented in Table 2 along with the values observed experimentally. A good agreement between the predicted values and the experimental ones was found. Therefore, the central composite design and regression analysis were effective in identifying the optimal $\mathrm{pH}$ and temperature conditions to maximize the

Table 2

Experimental runs using coded levels of Temperature $\left({ }^{\circ} \mathrm{C}\right)\left(\mathrm{X}_{1}\right)$ and $\mathrm{pH}\left(\mathrm{X}_{2}\right)$ according to the $2^{2}$ full factorial central composite design and yields of FOS production obtained under those conditions.

\begin{tabular}{|c|c|c|c|c|c|}
\hline \multirow[t]{2}{*}{ Runs } & \multicolumn{2}{|c|}{ Independent variables } & \multicolumn{3}{|c|}{ Yield ( $\left.\%\left(\mathrm{~g}_{\text {Fos }} \cdot \mathrm{g}_{\text {initial sucrose }}{ }^{-1}\right)\right)$} \\
\hline & $\mathrm{X}_{1}$ & $\mathrm{X}_{2}$ & Experimental & Predicted & Residues \\
\hline 1 & -1 & -1 & 42.80 & 44.16 & 1.37 \\
\hline 2 & -1 & 0 & 48.62 & 45.98 & -2.63 \\
\hline 3 & -1 & 1 & 46.41 & 47.68 & 1.27 \\
\hline 4 & 0 & -1 & 47.14 & 46.25 & -0.89 \\
\hline 5 & 0 & 0 & 53.56 & 53.40 & -0.16 \\
\hline 6 & 0 & 0 & 53.56 & 54.67 & 1.10 \\
\hline 7 & 0 & 0 & 53.56 & 54.21 & 0.65 \\
\hline 8 & 0 & 1 & 51.95 & 51.25 & -0.70 \\
\hline 9 & 1 & -1 & 48.64 & 48.17 & -0.47 \\
\hline 10 & 1 & 0 & 55.66 & 56.71 & 1.04 \\
\hline 11 & 1 & 1 & 54.65 & 54.08 & -0.57 \\
\hline
\end{tabular}


Table 3

Statistical analysis of the full Central Composite Design with two factors used for the optimization of FOS production.

\begin{tabular}{lllll}
\hline $\begin{array}{l}\text { Variables and } \\
\text { interactions }\end{array}$ & Estimated effects & Standard errors & $t$-value & $p$ \\
\hline $\mathrm{X}_{1}$ & 7.046 & 1.415 & 4.980 & $0.004^{\mathrm{a}}$ \\
$\mathrm{X}_{1}{ }^{2}$ & -2.840 & 2.177 & -1.304 & 0.249 \\
$\mathrm{X}_{2}$ & 4.811 & 1.415 & 3.400 & $0.019^{\mathrm{a}}$ \\
$\mathrm{X}_{2}{ }^{2}$ & -8.030 & 2.177 & -3.688 & $0.014^{\mathrm{a}}$ \\
$\mathrm{X}_{1} \mathrm{X}_{2}$ & 1.200 & 1.733 & 0.692 & 0.520 \\
\hline
\end{tabular}

$\mathrm{X}_{1}=$ coded values of temperature; $\mathrm{X}_{2}=$ coded values of $\mathrm{pH}$.

${ }^{a}$ Significant influence at $95 \%$ confidence level.

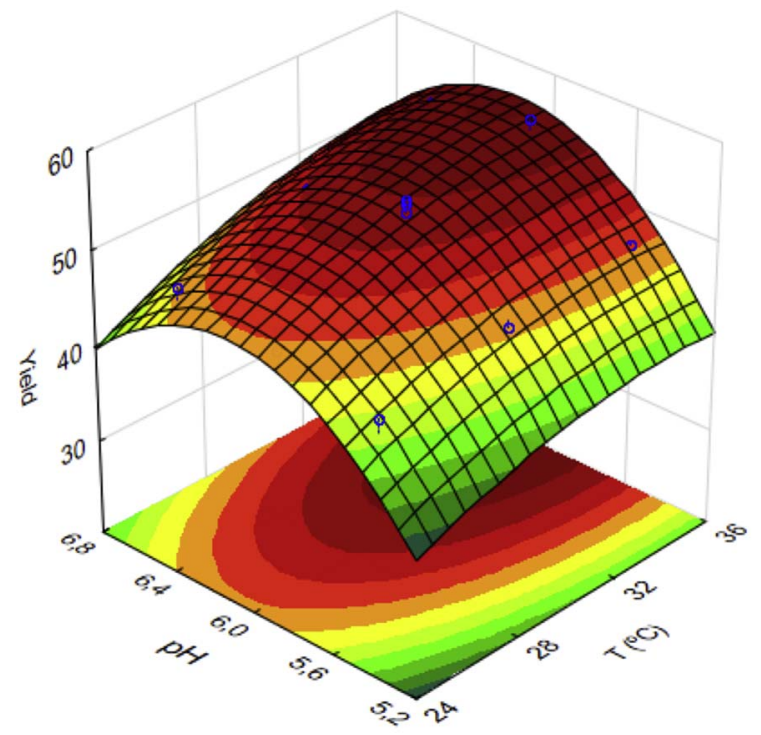

$>50$

Fig. 1. Response surface of the full Central Composite Design for the optimization of the FOS production yield ( $\mathrm{g}_{\mathrm{FOS}} \cdot \mathrm{g}_{\text {initial sucrose }}{ }^{-1}$ ) as a function of the $\mathrm{pH}$ and the temperature $\left({ }^{\circ} \mathrm{C}\right)$ conditions.

\section{production of FOS.}

The effect of the independent variables ( $\mathrm{pH}$ and Temperature) on FOS production yield can be better visualized by examining the surface plot shown in Fig. 1.

The response surface (Fig. 1) clearly shows that the FOS production yield is favoured by the linear increase of temperature, while for $\mathrm{pH}$, an optimum point was found after which higher $\mathrm{pH}$ values did not improve the FOS production yields.

An estimate of the optimum point revealed that a temperature of $37^{\circ} \mathrm{C}$ and a working $\mathrm{pH}$ of 6.2 may lead to a maximum FOS production yield. Under these conditions the model predicted a FOS production yield of $0.56 \mathrm{~g}_{\mathrm{FOS}} \cdot \mathrm{g}_{\text {initial sucrose }}{ }^{-1}$.

In order to validate the fitted model, four assays were performed under the estimated optimum operating conditions. A FOS production yield of $0.53 \pm 0.03 \mathrm{~g}_{\text {FOS. }} \cdot \mathrm{g}_{\text {initial sucrose }}{ }^{-1}$ was obtained, with a content of $101.1 \pm 8.2$ g.L - $^{-1}$ of FOS and a purity of $50.8 \pm 0.9 \%$. The FOS production yield values found experimentally are in good agreement with the predicted ones, again confirming the significance of the model.

\subsection{FOS production in bioreactor}

To scale-up the bioprocess, assays were performed in a bioreactor under the optimized operating conditions previously discussed. Fig. 2 shows the concentration profile of the sucrose consumed and the respective FOS formed. The maximum amount of FOS formed (Total FOS)

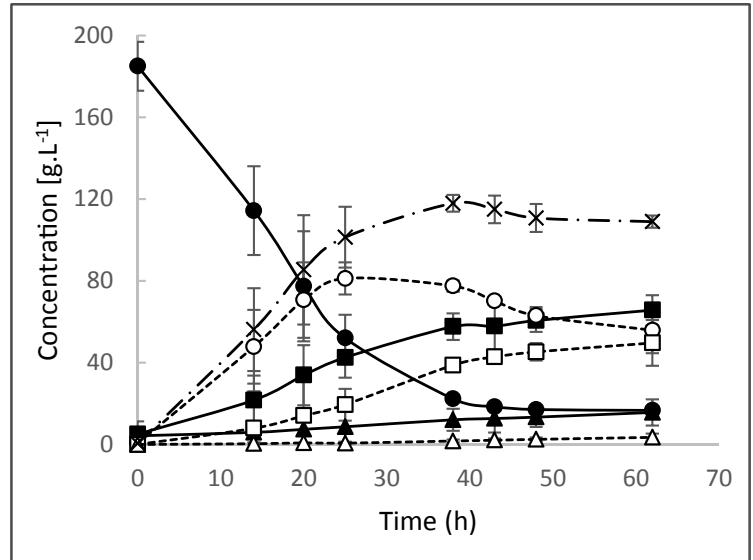

Fig. 2. Time course of the production of fructo-oligosaccharides (FOS) by Aspergillus ibericus in a bioreactor at $37{ }^{\circ} \mathrm{C}, \mathrm{pH} 6.2$ and $200 \mathrm{rpm}$. Fructose $(\boldsymbol{\Lambda})$, glucose $(\boldsymbol{\square})$, sucrose $(\bullet), \mathrm{GF}_{2}(\bigcirc), \mathrm{GF}_{3}(\square), \mathrm{GF}_{4}(\Delta)$ and total FOS $(\times)$. Results correspond to the average of 3 independent assays \pm confidence interval (95\% confidence level).

was obtained after $38 \mathrm{~h}$ of fermentation yielding $0.64 \pm 0.02$ $\mathrm{g}_{\text {FOS. }}$ ginitial sucrose $^{-1}$, with a content of $118 \pm 4$ g.L $\mathrm{L}^{-1}$ in FOS and a purity of $56 \pm 3 \%$. At this time point, the FOS mixture composition was $37 \pm 3 \%$ of $\mathrm{GF}_{2}, 18 \pm 2 \%$ of $\mathrm{GF}_{3}$ and $0.8 \pm 0.3 \%$ of $\mathrm{GF}_{4}$. The productivity of the process was found as $3.1 \pm 0.102 \mathrm{~g}_{\mathrm{FOS}} \cdot \mathrm{L}^{-1} \cdot \mathrm{h}^{-1}$.

The time required to achieve the maximum concentration of $\mathrm{GF}_{2}$ was $25 \mathrm{~h}\left(81 \pm 8 \mathrm{~g} . \mathrm{L}^{-1}\right)$. After this period, $\mathrm{GF}_{2}$ concentration started to decrease due to the formation of the $\mathrm{GF}_{3}$, by transfructosylation of fructose with $\mathrm{GF}_{2}$, and due to the activity of the hydrolysis enzymes converting $\mathrm{GF}_{2}$ back to fructose and sucrose. At $62 \mathrm{~h}$ of fermentation both $\mathrm{GF}_{3}$ and $\mathrm{GF}_{4}$ concentrations were still increasing, and the FOS total concentration did not decrease significantly from its maximum $\left(109 \pm 3\right.$ g.L $L^{-1}$ at $\left.62 \mathrm{~h}\right)$. An average of $113 \pm 4$ g.L $\mathrm{L}^{-1}$ of FOS was achieved from 38 to $62 \mathrm{~h}$. Thus, through the selection of different harvesting fermentation times, it is possible to obtain a variety of mixtures containing different ratios of oligosaccharides although with an equivalent total amount of FOS ( $66-51 \%$ of $\mathrm{GF}_{2}$ and $33-46 \%$ of $\mathrm{GF}_{3}$ in total FOS, between 38 and $62 \mathrm{~h}$ ).

The FOS production yield increased in the assays performed in bioreactor as compared to the shaken flasks. This increase is probably related with different mixture patterns obtained due to the reactor configuration, as well as with the $\mathrm{pH}$ control during fermentation. The agitation is substantially different, promoting different mixture conditions in the liquid and levels of aeration. To minimize the effect of the different volume headspaces and liquid surface areas in contact with the air of both set of experiments (Erlenmeyer versus bioreactor), a higher rotation was used in the assays conducted in the bioreactor to guarantee a better aeration of the medium, since the fungus is an aerobic microorganism (200 rpm instead of $150 \mathrm{rpm}$ used in the shaken flask assays). Actually, this was the main reason why agitation was not included as variable in the experimental design for the optimization of FOS production in shaken flasks. This parameter will have to be further optimized at the bioreactor scale taking into account its mixture and agitation patterns. During submerged cultivation in stirred fermenter, the agitation intensity has been reported to influence the fungal morphology and the specific energy dissipation rate (Cui, van der Lans, \& Luyben, 1997). The pellet may be damaged by the impellers of the reactor, contributing to free filamentous mycelia and reseed their growth, what ultimately can result in an increase of FOS production by the enzymes being produced by the highest biomass level.

A broad range of FOS production yields has been reported for other Aspergillus strains, varying from 0.20 to $0.60\left(\mathrm{~g}_{\mathrm{FOS}} \cdot \mathrm{g}_{\text {initial }}\right.$ sucrose $\left.^{-1}\right)$ (Dominguez et al., 2013). A. flavus, A. japonicus, A. niger and A. oryzae are between the Apergillus strains reported as FOS producers. The FOS production yield depends not only on the strain used, but also on the 
production process employed. Predominantly, FOS have been produced in a two-stage process using isolated enzymes produced by submerged fermentation (Sangeetha et al., 2005). Herein, FOS were produced using the whole cells of the $A$. ibericus avoiding the enzyme purification step. Production yields up to $0.64 \pm 0.02 \mathrm{~g}_{\text {Fos }} \cdot \mathrm{g}_{\text {initial sucrose }}{ }^{-1}$ were achieved. The process proved to be not only faster but also more economical as higher FOS production yields have been attained. Similarly, high production levels of FOS were obtained in our recent work conducted with the whole cells of $A$. pullulans ( $0.63 \mathrm{~g}_{\text {Fos. }} \mathrm{g}_{\text {initial sucrose }}{ }^{-1}$ ) (Dominguez et al., 2012; Nobre et al., 2016) and A. japonicus (0.61 $\mathrm{g}_{\text {Fos. }}$ g $_{\text {initial sucrose }}{ }^{-1}$ ) (Mussatto, Aguilar, Rodrigues, \& Teixeira, 2009). The use of one-step fermentation has been reported also for other microorganisms, although with yields much lower than the ones herein reported, such as Microbacterium paraoxydans with $0.38 \mathrm{~g}_{\mathrm{FO}} \cdot \mathrm{g}_{\text {initial su- }}$ crose $^{-1}$ (Ojha, Rana, \& Mishra, 2016) and Penicillium expansum with 0.58 $\mathrm{g}_{\text {Fos }} \cdot \mathrm{g}_{\text {initial sucrose }}{ }^{-1}$ (Prata, Mussatto, Rodrigues, \& Teixeira, 2010).

The $A$. ibericus was studied for the production of FOS since a positive reaction was obtained in preliminary tests made in agar plates with this fungus while screening for transfructosylation activity (Dominguez et al., 2006). The main goal of the current work was to determine the potential for FOS production of this new isolate (A. ibericus) and to chemically characterize the FOS mixture produced. The best temperature and $\mathrm{pH}$ conditions for the production of FOS by this organism were established.

Although the production yields obtained were considerably high as compared to other works (Dominguez et al., 2013), we believe that further optimizations are still required whenever scaling-up the bioprocess to bioreactors, namely in what concerns agitation rates and dissolved oxygen, which could possibly increase further the production yields. Moreover, alternative culture media based on food industry byproducts and residues may also be considered to optimize the FOS production yields and to improve the bioprocess sustainability. Additionally, downstream techniques could be employed for FOS purification such as Simulated Moving Bed chromatography or microbial treatment (Nobre, Teixeira, et al., 2015).

\subsection{HPLC characterization of the FOS produced by A. ibericus}

Fig. 3 shows the chromatographic profile obtained for a sample of the fermentation conducted with the A. ibericus as compared to the standard FOS from Wako.

The HPLC chromatogram analysis revealed that $A$. ibericus was able to produce three different oligosaccharides with retention times of 9.521 (DP2), 12.176 (DP3) and $15.920 \mathrm{~min}$ (DP4). The retention times were identical with that of the standards 1-kestose (9.560 min), nystose (12.191 min) and $1^{\mathrm{F}}$-fructofuranosylnystose (15.886 min) confirming the production of these three FOS by the A. ibericus. The three other peaks obtained earlier for the fermentative sample represent fructose

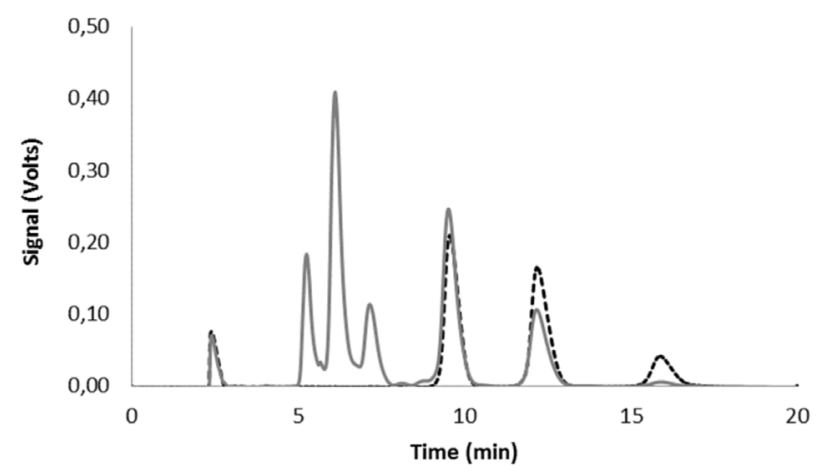

Fig. 3. HPLC chromatogram obtained for a sample of the fermentative broth from the Aspergilus ibericus culture (grey line) and the standard kestose, nystose, and $1^{\mathrm{F}}$-fructofuranosylnystose from Wako (dash black line). Samples were eluted at $1 \mathrm{~mL} \cdot \mathrm{min}^{-1}$ and $25{ }^{\circ} \mathrm{C}$ in a Prevail Carbohydrate ES column.
(5.252 $\mathrm{min})$, glucose (6.112 $\mathrm{min})$ and sucrose (7.153 $\mathrm{min})$.

\subsection{NMR characterization of the FOS produced by A. ibericus}

The prebiotic activity of sugars is mainly dependent on their chemical structure (Borromei et al., 2009). Composition of the oligosaccharides and linkages between the monomers may influence their digestion by the colonic microflora and by the salivary, pancreatic and brush border human enzymes (Suzuki, Tanaka, Amano, Asakura, \& Muramatsu, 2004). Therefore, the chemical structure of the FOS mixture synthesised by $A$. ibericus in the present work was determined.

FOS were firstly purified up to $93 \%(w / w)$ in an activated charcoal column through selective desorption using ethanol concentration gradients to obtain the IB mixture (Nobre et al., 2012). The same procedure was used for the FOS synthesised by A. pullulans in our previous work (Nobre et al., 2016). Finally, FOS chemical structures were identified by NMR and compared with a commercially available Actilight FOS mixture and Wako FOS standards.

The NMR characteristics as ${ }^{1} \mathrm{H}$ and ${ }^{13} \mathrm{C}$ chemical shifts, correlations (coupling constants) and integration values obtained for the three samples (AP, IB and Actilight) were equal, and therefore, corresponding to FOS with same substitution pattern and degree of polymerization (DP). In addition, the FOS structures observed in the ${ }^{1} \mathrm{H}^{13} \mathrm{C}$ HSQC spectra from these three samples presented equal ${ }^{1} \mathrm{H}$ and ${ }^{13} \mathrm{C}$ interactions when compared to the ${ }^{1} \mathrm{H}_{-}{ }^{13} \mathrm{C}$ HSQC spectrum from a mixture of standard FOS from Wako (Neuss, Germany) containing $\mathrm{GF}_{2}$ (1-kestose), $\mathrm{GF}_{3}$ (nystose), and $\mathrm{GF}_{4}$ ( $1^{\mathrm{F}}$-fructofuranosylnystose).

In Fig. 4 it is possible to observe the similarity of the spin systems between the ${ }^{1} \mathrm{H}_{-}{ }^{13} \mathrm{C}$ HSQC NMR spectra from the standard FOS from Wako (a) and the sample IB (b), since the other spectra (AP and Actilight) were equal. In addition, the signals in Fig. $4 \mathrm{a}$ were assigned and labeled according to the 1-kestose structure. The COSY and HSQC spectra permitted assigning the spin systems, while the connectivity was known from cross peaks in the HMBC spectrum (data not shown). Moreover, the complete hydrogen assignments were obtained by means of HMBC and ${ }^{13} \mathrm{C}$ NMR (Santos-Moriano et al., 2015).

The ${ }^{1} \mathrm{H}$ NMR spectra showed the presence of signals in the anomeric region between the chemical shifts $\delta 5.37-5.48$ (duplets $3.9 \mathrm{~Hz}$ ), others previously identified signals between $\delta 4.18-4.30$ and $\delta 4.02-4.14$, and those between $\delta 3.44$ and $\delta 3.93$ (Liao et al., 2011). The anomeric regions in ${ }^{13} \mathrm{C}$ NMR spectra were more complex presenting overlapping resonances between $\delta 105.8-106.6$ and $\delta$ 94.8-95.5. Signals for FRU units were recognized by their downfield positions at $\delta 105.8-106.6$, which present cross peaks with the units GLU H1 $(\delta 5.37-5.48)$ and FRU $\mathrm{H} 1 \mathrm{a}$ and H1b (different conformations of FRU between $\delta$ 3.74-3.87). The connectivity between GLU and FRU units was determined from the existence of a cross peak between the H1 from GLU unit and the quaternary carbon C2 from FRU unit in the HMBC spectrum. The occurrence of a cross peak between $\mathrm{H} 1$ of the GLU unit and C2 of a FRU unit and the concomitant absence of correlations between quaternary C2 of FRU unit and H2, 3, 4 and/or 6 of the GLU unit favoured the position of the GLU unit in the beginning of the chain. Moreover, the presence of characteristic chemical shifts for C3 and C4 of the FRU units at $\delta$ 76.6-77.4 was also indicative of the connection between C1 and C2 of the FRU units. This observation combined with the DP estimated from the integration of the signals between $\delta$ 5.37-5.48 and those at $\delta$ $4.18-4.30$ and $\delta 4.02-4.14$ were in favour to the linear structure of the FRU units.

Furthermore, the spin systems of the three samples (AP, IB and Actilight) allowed establishing the presence of the main correlations of the compounds as: ... H1 $\beta$ FRU C2 $\rightarrow \mathrm{H} 1$ FFRU C2 $\rightarrow \mathrm{H} 1$ aGLU. The constant coupling $\left(\mathrm{J}_{\mathrm{H}-\mathrm{H}}\right)$ observed in Table 4 were obtained by the $J$ resolved and only approximated chemical shifts $(\delta)$ were obtained due to signals overlap spin systems. 

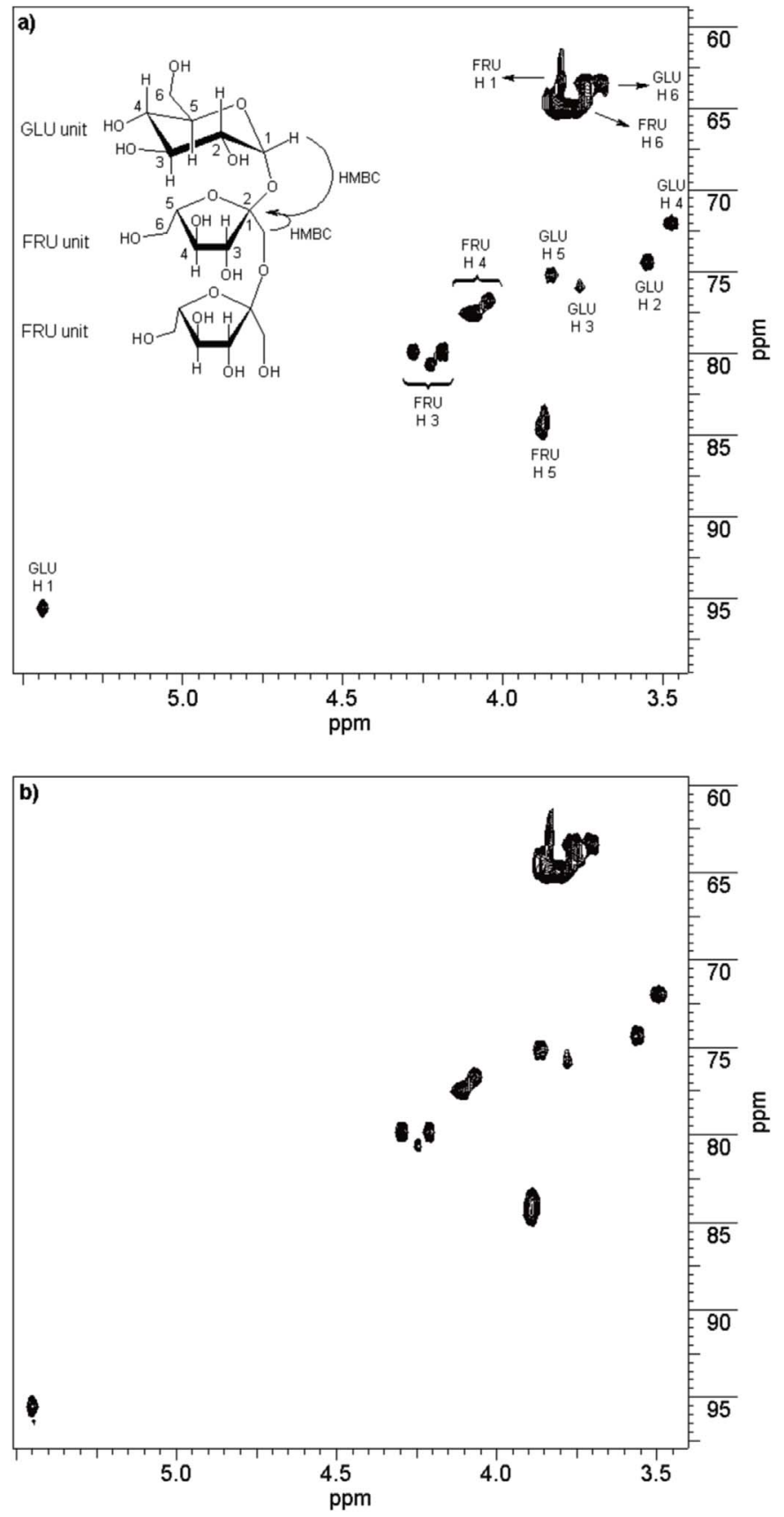

Fig. 4. Comparison between the ${ }^{1} \mathrm{H}_{-}{ }^{13} \mathrm{C}$ HSQC NMR spectra from the samples: a) standard FOS sample from Wako supplier $\left(\mathrm{GF}_{2}, \mathrm{GF}_{3}\right.$, and $\left.\mathrm{GF}_{4}\right)$; b) FOS sample produced by Aspergillus ibericus.

\section{Conclusions}

A temperature of $37{ }^{\circ} \mathrm{C}$ and a pH 6.2 were established by experimental design as the optimal fermentation conditions to produce FOS by $A$. ibericus. Experiments run in bioreactor in a one-stage process, using the whole cells of the microorganism, resulted in a FOS production of $0.64 \pm 0.02 \mathrm{~g}_{\mathrm{FOS}}$ g $_{\text {initial sucrose }}{ }^{-1}$ at $38 \mathrm{~h}$ of fermentation, with a content of $118 \pm 4$ g.L $\mathrm{L}^{-1}$ in FOS and purity of $56 \pm 3 \%$. The FOS produced were identified by NMR and HPLC as 1-kestose, nystose, and $1^{\mathrm{F}}$-fructofuranosylnystose.

The results gathered in this study highlight the possibility of using the fungus A. ibericus MUM 03.49 as a prebiotic producer at a large scale.
Table 4

Chemical shifts (in ppm) of ${ }^{1} \mathrm{H}$ and ${ }^{13} \mathrm{C}$, and constant coupling (in $\mathrm{Hz}$ ) of all fructo-oligosaccharides (FOS) present in the four samples under study, namely: (IB) the FOS mixture produced in this work by Aspergillus ibericus; (AP) a FOS mixture produced by Aureobasidium pullulans CCY 27-1-94, Actilight mixture, and FOS from Wako.

\begin{tabular}{llll}
\hline Unit/Carbon & $\delta^{1} \mathrm{H}$ & multiplicity $^{\mathrm{a}} ; \mathrm{J}$ in $\mathrm{Hz}$ & ${ }^{13} \mathrm{C}$ \\
\hline GLU C1 & $5.37-5.48$ & $d 3.9$ & $94.8-95.5$ \\
GLU C2 & $3.53-5.48$ & $d d 3.9,10.0$ & $73.5-74.6$ \\
GLU C3 & $3.73-3.79$ & $m$ & $75.0-76.0$ \\
GLU C4 & $3.45-3.51$ & $m$ & $71.6-72.7$ \\
GLU C5 & $3.82-3.88$ & $m$ & $74.8-75.9$ \\
GLU C6 & $3.80-3.89$ & $d 10.4$ & $63.4-64.5$ \\
FRU C1 & $3.67-3.71$ & $s$ & $62.8-63.8$ \\
FRU C2 & - & - & $105.8-106.6$ \\
FRU C3 & $4.18-4.30$ & $d 8.6$ & $79.1-80.7$ \\
FRU C4 & $4.02-4.14$ & $m$ & $76.3-77.8$ \\
FRU C5 & $3.84-3.90$ & $m$ & $83.5-84.6$ \\
FRU C6 & $3.74-3.87$ & $m$ & $64.6-65.8$ \\
\hline
\end{tabular}

${ }^{\mathrm{a}} s$ - singlet; GLU - glucose; FRU - fructose; $d$ - doublet; $d d$ - doublet of doublets; $m$ multiplet.

\section{Acknowledgements}

Clarisse Nobre acknowledges the Portuguese Foundation for Science and Technology (FCT) for her Post-Doc Grant [ref. SFRH/BPD/87498/ 2012] and the project RECI/BBB-EBI/0179/2012 (FCOMP-01-0124FEDER-027462), the strategic funding of UID/BIO/04469/2013 unit, COMPETE 2020 (POCI-01-0145-FEDER-006684), BioTecNorte operation (NORTE-01-0145-FEDER-000004) and the project MultiBiorefinery (POCI-01-0145-FEDER-016403) funded by European Regional Development Fund under the scope of Norte2020 - Programa Operacional Regional do Norte.

\section{References}

Bali, V., Panesar, P. S., Bera, M. B., \& Panesar, R. (2015). Fructo-oligosaccharides: Production, purification and potential applications. Critical Reviews in Food Science and Nutrition, 55(11), 1475-1490.

Borromei, C., Careri, M., Cavazza, A., Corradini, C., Elviri, L., Mangia, A., et al (2009). Evaluation of fructooligosaccharides and inulins as potentially health benefiting food ingredients by HPAEC-PED and MALDI-TOF MS. International Journal of Analytical Chemistry 530639.

Castro, C. C., Nobre, C., Duprez, M.-E., De Weireld, G., \& Hantson, A.-L. (2017). Screening and selection of potential carriers to immobilize Aureobasidium pullulans cells for fructo-oligosaccharides production. Biochemical Engineering Journal, 118, 82-90.

Cui, Y. Q., van der Lans, R. G. J. M., \& Luyben, K. C. A. M. (1997). Effect of agitation intensities on fungal morphology of submerged fermentation. Biotechnology and Bioengineering, 55(5), 715-726.

Dominguez, A., Nobre, C., Rodrigues, L. R., Peres, A. M., Torres, D., Rocha, I., et al. (2012). New improved method for fructooligosaccharides production by Aureobasidium pullulans. Carbohydrate Polymers, 89(4), 1174-1179.

Dominguez, A. L., Rodrigues, L. R., Lima, N. M., \& Teixeira, J. A. (2013). An overview of the recent developments on fructooligosaccharide production and applications. Food and Bioprocess Technology, 7, 324-337.

Dominguez, A., Santos, I. M., Teixeira, J. a, \& Lima, N. (2006). New and simple plate test for screening relative transfructosylation activity of fungi. Revista Iberoamericana de Micologia: Organo de La Asociacion Espanola de Especialistas En Micologia, Vol. 23, 189-191.

Flint, H. J., Scott, K. P., Louis, P., \& Duncan, S. H. (2012). The role of the gut microbiota in nutrition and health. Nature reviews. Gastroenterology \& Hepatology, 9(10), 577-589.

Ganaie, M. A., Lateef, A., \& Gupta, U. S. (2014). Enzymatic trends of fructooligosaccharides production by microorganisms. Applied Biochemistry and Biotechnology, 172(4), 2143-2159.

Gomes, A. J. P. (2009). Optimização da Produção de Frutooligossacáridos por AspergillusUnpublished master's thesis. Braga, Portugal: University of Minho.

Liao, L. M., Alves Filho, E. G., Silva, L. M. A., Choze, R., Alcantara, G. B., \& Bassinello, P. Z. (2011). Quantification of oligosaccharides from common beans by HR-MAS NMR. Magnetic resonance in food Science: An exciting future (pp. 47-53). The Royal Society of Chemistry.

Li, W., Wang, K., Sun, Y., Ye, H., Hu, B., \& Zeng, X. (2015). Influences of structures of galactooligosaccharides and fructooligosaccharides on the fermentation in vitro by human intestinal microbiota. Journal of Functional Foods, 13, 158-168.

Mussatto, S. I., Aguilar, C. N., Rodrigues, L. R., \& Teixeira, J. A. (2009). Colonization of Aspergillus japonicus on synthetic materials and application to the production of fructooligosaccharides. Carbohydrate Research, 344(6), 795-800.

Nishizawa, K., Nakajima, M., \& Nabetani, H. (2001). Kinetic Study on transfructosylation 
by $\beta$-fructofuranosidase from Aspergillus Niger ATCC 20611 and availability of a membrane reactor for fructooligosaccharide production. Food Science and Technology Research, 7(1), 39-44.

Nobre, C., Castro, C. C., Hantson, A.-L., Teixeira, J. A., De Weireld, G., \& Rodrigues, L. R. (2016). Strategies for the production of high-content fructo-oligosaccharides through the removal of small saccharides by co-culture or successive fermentation with yeast. Carbohydrate Polymers, 136, 274-281.

Nobre, C., Cerqueira, M.Â., Rodrigues, L. R., Vicente, A. A., \& Teixeira, J. A. (2015). Production and extraction of polysaccharides and oligosaccharides and their use as new food additives. Industrial biorefineries \& white biotechnology (pp. 653-679). Elsevier B.V.

Nobre, C., Santos, M. J., Dominguez, A., Torres, D., Rocha, O., Peres, A. M., et al. (2009). Comparison of adsorption equilibrium of fructose, glucose and sucrose on potassium gel-type and macroporous sodium ion-exchange resins. Analytica Chimica Acta, 654(1), 71-76.

Nobre, C., Teixeira, J. A., \& Rodrigues, L. R. (2012). Fructo-oligosaccharides purification from a fermentative broth using an activated charcoal column. New Biotechnology, 29(3), 395-401.

Nobre, C., Teixeira, J. A., \& Rodrigues, L. R. (2015). New trends and technological challenges in the industrial production and purification of fructo-oligosaccharides. Critical Reviews in Food Science and Nutrition, 55(10), 1444-1455.

Ojha, S., Rana, N., \& Mishra, S. (2016). Fructo-oligosaccharide synthesis by whole cells of Microbacterium paraoxydans. Tetrahedron: Asymmetry, 27(24), 1245-1252.

Prata, M. B., Mussatto, S. I., Rodrigues, L. R., \& Teixeira, J. A. (2010).

Fructooligosaccharide production by Penicillium expansum. Biotechnology Letters, 32(6), 837-840.

Rastall, R. A., Gibson, G. R., Gill, H. S., Guarner, F., Klaenhammer, T. R., Pot, B., et al (2005). Modulation of the microbial ecology of the human colon by probiotics, prebiotics and synbiotics to enhance human health: An overview of enabling science and potential applications. FEMS Microbiology Ecology, 52(2), 145-152.

Sabater-Molina, M., Larqué, E., Torrella, F., \& Zamora, S. (2009). Dietary fructooligosaccharides and potential benefits on health. Journal of Physiology and Biochemistry, 65(3), 315-328.

Sangeetha, P. T., Ramesh, M. N., \& Prapulla, S. G. (2005). Maximization of fructooligosaccharide production by two stage continuous process and its scale up. Journal of Food Engineering, 68(1), 57-64.

Santos-Moriano, P., Fernandez-Arrojo, L., Poveda, A., Jimenez-Barbero, J., Ballesteros, A. O., \& Plou, F. J. (2015). Levan versus fructooligosaccharide synthesis using the levansucrasefrom Zymomonas mobilis: Effect of reaction conditions. Journal of Molecular Cataysis B: Enzymatic, 119, 18-25.

Scheid, M. M. A., Moreno, Y. M. F., Maróstica Junior, M. R., \& Pastore, G. M. (2013). Effect of prebiotics on the health of the elderly. Food Research International.

Serra, R., Cabañes, F. J., Perrone, G., Castellá, G., Venâncio, A., Mulè, G., et al. (2006). Aspergillus ibericus: A new species of section Nigri isolated from grapes. Mycologia, 98(2), 295-306.

Silva, M. F., Rigo, D., Mossi, V., Golunski, S., Kuhn, G. O., Di Luccio, M., et al. (2013). Enzymatic synthesis of fructooligosaccharides by inulinases from Aspergillus Niger and Kluyveromyces marxianus NRRL Y-7571 in aqueous-organic medium. Food Chemistry, 138(1), 148-153.

Slavin, J. (2013). Fiber and Prebiotics: Mechanisms and health benefits. Nutrients, 5, 1417-1435.

Suzuki, Y., Tanaka, K., Amano, T., Asakura, T., \& Muramatsu, N. (2004). Utilization by intestinal bacteria and digestibility of arabino-oligosaccharides. Journal of the Japanese Society for Horticultural Science, 73(6), 574-579.

Vandáková, M., Platková, Z., Antošová, M., Báleš, V., \& Polakovič, M. (2004). Optimization of cultivation conditions for production of fructosyltransferase by Aureobasidium pullulans. Chemical Papers, 58(1), 15-22.

Wang, Y. (2009). Prebiotics: Present and future in food science and technology. Food Research International, 42(1), 8-12.

Younis, K., Ahmad, S., \& Jahan, K. (2015). Health benefits and application of prebiotics in foods. Journal of Food Processing \& Technology, 6(4), 1-7. 